\title{
Sciatica due to heterotopic ossification: case illustration
}

\author{
William Omar Contreras Lopez, MD, PhD, ${ }^{1,2}$ Emiliano Neves Vialle, MD, ${ }^{2}$ \\ Danilo Costa Barbosa, MD, ${ }^{1}$ and Luiz Roberto Gomes Vialle, MD, PhD ${ }^{2}$
}

${ }^{1}$ Division of Neurosurgery, Department of Neurology, School of Medicine, University of São Paulo; and ${ }^{2}$ Spine Surgery Department, Hospital Universitário de Cajuru, Catholic University of Paraná, Curitiba, Brazil

http://thejns.org/doi/abs/10.3171/2014.10.SPINE14221

KEY WORDS sciatica; low-back pain; extraspinal compression; heterotopic ossification; posterior transgluteal approach; lumbar

A 33-year-old man was referred for surgical evaluation with a diagnosis of symptomatic lumbar disc herniation. His chief complaint was persistent sciatic pain on the right lower limb, aggravated by physical activity and prolonged sitting. He had a previous history of minor back pain.

A physical examination showed normal lumbar mobility, normal strength and reflexes on the lower limbs, and hypesthesia of L-4 and L-5 dermatomes of the right foot. Provocative tests for sacroiliac joints and piriformis muscle were negative, but there was limited, although painless, internal rotation of the right hip.

MRI showed moderate facet and flavum hypertrophy and disc protrusion that caused bilateral foraminal stenosis, more severe on the left side (Fig. 1 left). Due to the asymmetric hip examination results, pelvic radiographs were ordered, and a bone mass just below the ischial tuberosity was noted (Fig. 1 right). A CT scan revealed a heterotopic bone mass on the right at the level of the biceps femoris muscle (Fig. 2 left), adjacent to the sciatic nerve. A foraminal L4-5 nerve root block, performed for differential diagnosis, was negative.

A posterior transgluteal surgical approach was performed, achieving complete release of the sciatic nerve and extraction of the bone mass, which measured $6.5 \mathrm{~cm}$ in length (Fig. 2 right). Histopathological examination reported mature bone tissue, compatible with heterotopic ossifica- tion. The patient had fully recovered clinically 2 months after surgery, and follow-up imaging at 1 and 2 years showed no recurrence. In cases of sciatica, without clear clinical and radiological correlation, extraspinal causes should be investigated. $^{1-4}$

\section{References}

1. Kao CC, Uihlein A, Bickel WH, Soule EH: Lumbar intraspinal extradural ganglion cyst. J Neurosurg 29:168-172, 1968

2. Ludloff K: The open reduction of the congenital hip dislocation by an anterior incision. J Am Acad Orthop Surg 10:458-454, 1913

3. Panagiotopoulos EC, Syggelos SA, Plotas A, Tsigkas G, Dimopoulos P: Sciatica due to extrapelvic heterotopic ossification: a case report. J Med Case Reports 2:298, 2008

4. Sim FH, Dahlin DC, Stauffer RN, Laws ER Jr: Primary bone tumors simulating lumbar disc syndrome. Spine (Phila Pa 1976) 2:65-74, 1977

\footnotetext{
Author Contributions

Conception and design: Lopez, EN Vialle. Acquisition of data: Lopez, EN Vialle. Analysis and interpretation of data: Lopez, EN Vialle, Barbosa. Drafting the article: Lopez, EN Vialle. Critically revising the article: Lopez, Barbosa, LRG Vialle. Reviewed submitted version of manuscript: Lopez. Approved the final version of the manuscript on behalf of all authors: Lopez. Administrative/technical/material support: Lopez, LRG Vialle. Study supervision: Lopez.
} 


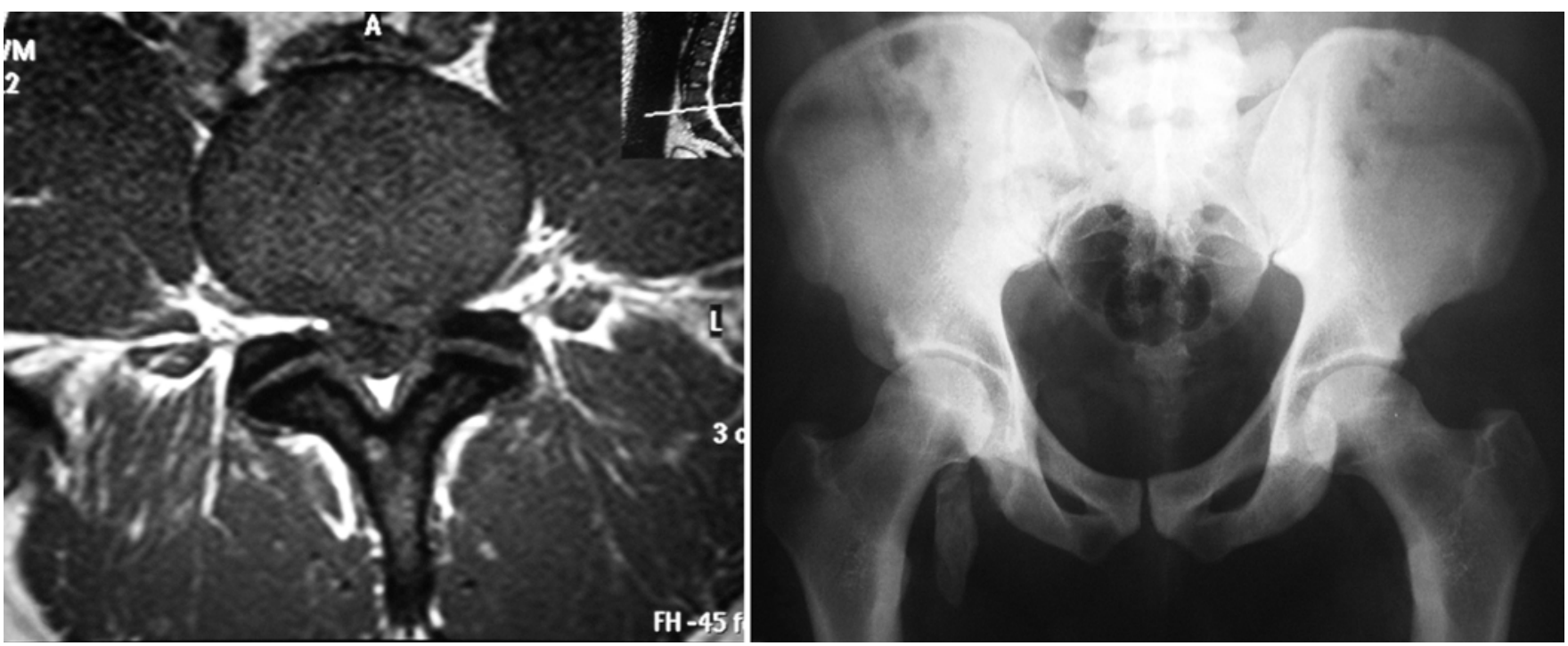

FIG. 1. Lumbar axial MR image (left) showing disc protrusion and foraminal stenosis at L4-5. Preoperative pelvic radiograph (right) showing heterotopic bone mass.
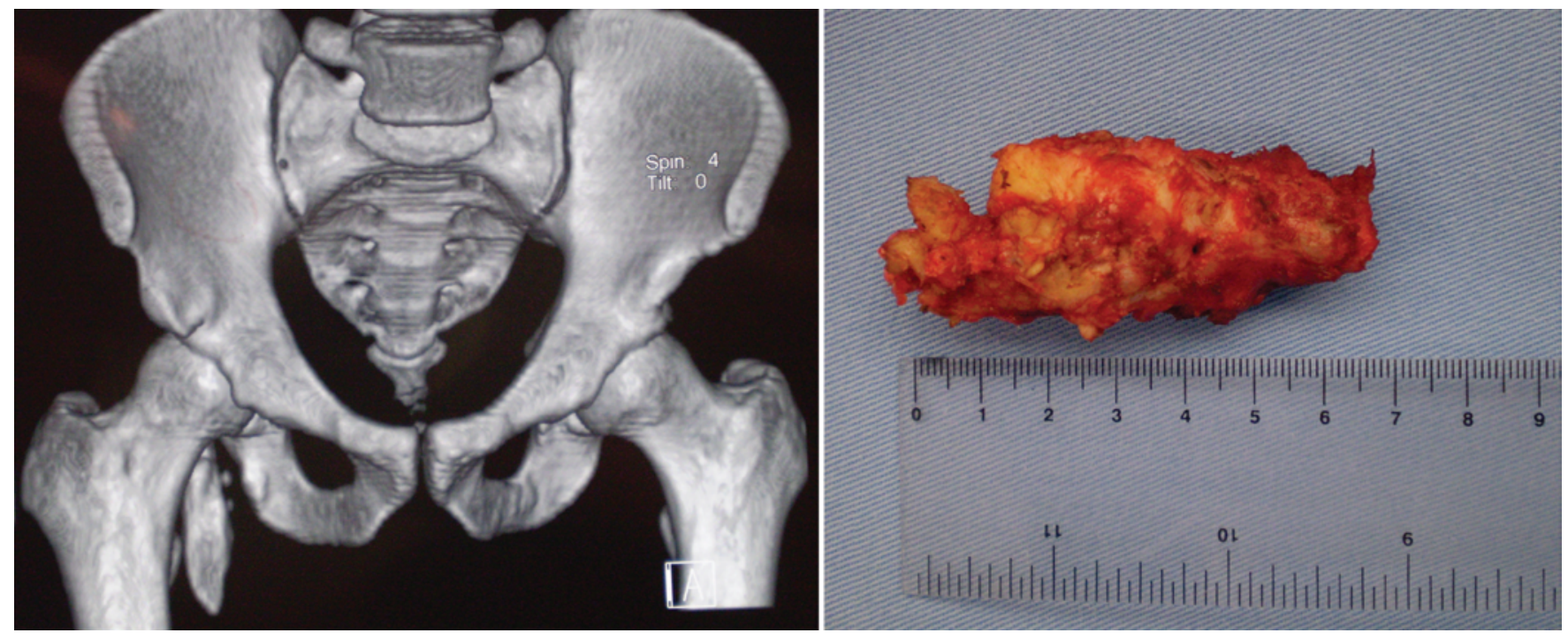

FIG. 2. A CT scan of the pelvis (left) revealed a heterotopic bone mass on the right side at the level of the biceps femoris muscle. The heterotopic bone mass (right), $6.5 \mathrm{~cm}$ in length, was dissected and removed. Figure is available in color online only. 